\title{
EL RÉGIMEN DE LAS AYUDAS DE ESTADO Y SU IMPACTO EN EL DERECHO ESPAÑOL
}

\author{
GERMÁN Fernández FARRERES \\ Catedrático de Derecho Administrativo \\ Universidad Complutense de Madrid
}

\begin{abstract}
RESUMEN
Tras una sucinta exposición del significado y rasgos generales del régimen comunitario de las ayudas de Estado, se analizan las principales medidas adoptadas para la adecuación del derecho español a sus exigencias y la posición que corresponde a los tribunales nacionales en su aplicación. Además, se destaca el influjo de ese régimen en la evolución de la normativa reguladora de la actividad administrativa consistente en el otorgamiento de subvenciones.
\end{abstract}

Palabras clave: ayudas de Estado; ayudas incompatibles, ayudas ilegales; ayudas abusivas; subvenciones; reintegro de subvenciones; recuperación de ayudas.

\begin{abstract}
After a brief exposition of the meaning and general features of the Community rules for State aid, the main measures taken to adapt the Spanish law to their demands and the position corresponding to national courts in its application are analyzed. In addition, the influence of that regime in the evolution of the rules governing administrative activity consisting of the provision of subsidies stands.
\end{abstract}

Key words: State aid; incompatible aid; illegal aid; abusive aid; subsidies; reimbursement of subsidies; recovery of aid. 


\section{SUMARIO}

I. Introducción.- II. PRincipales CARacterísticas del RÉgimen COMUNITARIo de LAS AYUDAS DE ESTADO.- III. LA ADECUACIÓN DEL ORDENAMIENTO JURÍDICO ESPAÑOL AL RÉGIMEN COMUNITARIO DE LAS AYUDAS DE ESTADO.- IV. APOSTILLA FINAL.

\section{INTRODUCCIÓN}

En 1986, en el momento del ingreso de España en la Comunidad Económica Europea, la doctrina española apenas había dedicado atención al estudio de la actividad administrativa mediante el establecimiento y otorgamiento de ayudas e incentivos económicos a la iniciativa privada. Más allá de descripciones generales de este tipo de actividad, tradicionalmente encuadrada en el llamado fomento administrativo, y de algunos estudios específicos de las técnicas de las que se sirve y que fueron apareciendo a lo largo de la primera mitad de los años ochenta, la falta de atención corrió paralela a la prácticamente inexistente regulación específica del actuar administrativo consistente en el otorgamiento de subvenciones y otras ayudas económicas.

No estará de más recordar que, durante mucho tiempo, la única regulación con pretensiones de generalidad fue la que se incorporó al Reglamento de Servicios de las Corporaciones Locales de 17 de junio de 1955; una regulación que, referida en exclusiva a las entidades locales, supuso en su momento un cierto avance, si bien pronto se reveló insuficiente. Aunque con el paso del tiempo no dejaron de adoptarse regulaciones sectoriales más o menos completas (caso significativo de la Ley 50/1985, de 27 de diciembre, de incentivos regionales para la corrección de desequilibrios económicos interterritoriales), hasta principios de la década de los años noventa esta situación no se empezó a corregir. La Ley 31/1990, de 27 de diciembre, de Presupuestos Generales del Estado para 1991 (artículo 16.3) dio nueva redacción a los artículos 81 y 82 del Texto Refundido de la Ley General Presupuestaria de 23 de septiembre de 1988 y fijó un marco normativo general para las ayudas y subvenciones públicas. Y, tras la Ley 30/1992, de 26 de noviembre, mediante Real Decreto 2225/1993, de 17 de diciembre, se aprobó el Reglamento de procedimiento para la concesión de subvenciones públicas, aunque, de una parte, su ámbito de aplicación quedó circunscrito a las subvenciones estatales, y, de otra, su contenido no presentó excesiva importancia, dado que en los aspectos fundamentales se limitó a remitir a lo que en las correspondientes normas reguladoras de cada tipo de subvención 
pudiera establecerse, reiterando en todo lo demás las previsiones contenidas en los artículos 81 y 82 de la Ley General Presupuestaria.

Esta manifiesta insuficiencia regulatoria, sólo años más tarde fue remediada con la aprobación de la Ley 38/2003, de 17 de noviembre, General de Subvenciones. No obstante, debe ya señalarse que al procederse - con toda lógica- a una acotación estricta del concepto de subvención, otras modalidades o formas de ayudas económicas quedaron al margen de la aplicación directa del régimen jurídico previsto para la misma, lo que, como más adelante veremos, no ha dejado de plantear alguna dificultad cuando se tiene que dar cumplimiento a decisiones de las autoridades comunitarias que declaran ilegal o incompatible con el derecho de la Unión Europea el otorgamiento de ayudas económicas que no son estrictamente subvenciones. Pero, en todo caso, ninguna duda cabe de que la Ley General de Subvenciones, con su Reglamento, aprobado por Real Decreto 887/2006, de 21 de julio, ha supuesto un importante avance en el esfuerzo por encuadrar jurídicamente el desarrollo de este tipo de actividad y, en consecuencia, por limitar la tradicional discrecionalidad que la ha caracterizado.

En contraste con esta falta de atención normativa, jurisprudencial y hasta doctrinal, a la cuestión de las ayudas públicas de carácter económico otorgadas para favorecer o mantener el desarrollo de actividades empresariales, industriales y comerciales, dada su incuestionable incidencia en las reglas de la libre competencia y en la existencia de un mercado único, las instituciones comunitarias le dispensaron desde el primer momento una atención prioritaria. Es lógico, de todas formas, esa diferente actitud. Dada la importancia y significación de las ayudas públicas para el funcionamiento del mercado en su conjunto y su capacidad de alterar la competencia y los intercambios comerciales, fácilmente se explica que la integración comunitaria impusiera el establecimiento de un conjunto de medidas tendentes a limitar y condicionar la autonomía de las políticas económicas de los Estados miembros. Y es que sin esas limitaciones, difícilmente podrían asegurarse las condiciones exigibles para la plena efectividad de los principios que constituyen la base misma del establecimiento de un auténtico mercado único y de un sistema de competencia no falseada. La construcción de un nuevo mercado obligó, en consecuencia, desde el mismo momento fundacional de la Comunidad Económica Europea, a organizar una auténtica policía económica garante de la compatibilidad de las acciones estatales con tales presupuestos básicos. Policía económica al servicio de lo que se ha dado en llamar integración negativa de las Comunidades Europeas, pero al servicio también de la aspiración última de materia- 
lizar su integración positiva. $\mathrm{O}$, dicho en otros términos, el proceso de la construcción del mercado único quedó enmarcado en un doble frente de acción. De un lado, tratando de reducir el desarrollo autónomo de las políticas económicas nacionales mediante el establecimiento y otorgamiento de ayudas a sus producciones nacionales, ya que, en otro caso, dificultarían, cuando no impedirían, la unificación del mercado. Pero, de otro, en tanto que esas ayudas pueden ser en determinados supuestos útiles instrumentos de intervención pública de los que no se puede prescindir, disponiendo a la vez que la competencia última para su adopción recayera en los propios órganos comunitarios, desplazando con ello al ámbito de responsabilidad de éstos el diseño y ejecución de la política general y de las acciones comunes a desarrollar en el marco económico y social del mercado comunitario ${ }^{1}$.

En todo caso, lo que interesa destacar es que el régimen comunitario de las ayudas de Estado (que, como es natural, resultaba ajeno por completo al ordenamiento jurídico español de 1986 y, por ello, prácticamente desconocido), a partir de la integración comunitaria despertó un notable interés y una progresiva atención ${ }^{2}$. Además, la aplicación del

1 Conviene resaltar que estamos en presencia de una modalidad de intervencionismo económico que, aun cuando conlleve alteraciones o distorsiones de la competencia, su total erradicación no resulta razonable, ni lógica, ni tampoco posible. La simple constatación de que el juego del mercado por sí solo no permite alcanzar determinados desarrollos coherentes y armónicos territorialmente (lo que inevitablemente reclama la acción de los poderes públicos que, como un elemento básico de la política económica estructural, también se sirve del otorgamiento de ayudas económicas a la iniciativa privada), llevó, en consecuencia, al establecimiento de un régimen comunitario en el que el principio prohibitivo de las ayudas públicas habría de quedar ampliamente atemperado. Una atemperación consistente en someter las ayudas estatales al control comunitario y, asimismo, en que los propios órganos comunitarios pudieran establecer y hacer uso de esas mismas ayudas. Como ha señalado de continuo la Comisión Europea, las ayudas estatales pueden asegurar una adaptación ordenada hacia nuevas estructuras económicas viables a largo plazo, razón por la cual no debe adoptarse una actitud restrictiva respecto de las destinadas a corregir situaciones en las que las condiciones del mercado dificultan el progreso económico y social o no permiten alcanzarlo más que con demoras o repercusiones sociales inaceptables. Y, además, tampoco puede desconocerse que las ayudas pueden ser necesarias para corregir importantes desequilibrios regionales, o para facilitar o acelerar adaptaciones o desarrollos indispensables en ciertas industrias, o, en última instancia, para neutralizar, al menos temporalmente, aquellas distorsiones debidas a acciones de elementos externos a los propios Estados de la Unión. En definitiva, la «cohesión económica y social», concepto clave para facilitar un desarrollo armónico del conjunto de la Comunidad, reduciendo las diferencias entre las diversas regiones y el retraso de las menos favorecidas, reclama un amplio sistema de ayudas. Tanto es así que bien puede afirmarse que el esfuerzo prioritario desarrollado por los órganos comunitarios se ha centrado en encauzar y dirigir, más que en prohibir taxativamente, las políticas estatales en materia de ayudas. Esto ha determinado, simultáneamente, el surgimiento y consolidación de una política comunitaria propia, buscando, a través del otorgamiento de ayudas con cargo a fondos comunitarios y enmarcando los objetivos y condiciones de las otorgadas por los Estados, un desarrollo estable y equilibrado de la Unión en su conjunto.

2 Tanto es así que, en la actualidad, la bibliografía española sobre el régimen de las ayudas de Estado, dando cumplida cuenta de la jurisprudencia comunitaria, comienza a ser sobreabundante, sucediéndose las aportaciones de manera incesante. Sin perjuicio de otras que 
régimen de las ayudas de Estado de inmediato puso de manifiesto que era preciso articular un conjunto de medidas normativas al servicio de garantizar una efectiva observancia de las decisiones comunitarias. Y, a la vez, yendo más allá de la concreta finalidad inspiradora de la regulación comunitaria, también sirvió de estímulo para que progresivamente se fuera tomando conciencia de la necesidad de contar con un marco normativo ordenador de una actividad que se venía desenvolviendo en el ámbito de la más absoluta discrecionalidad. Y así, aunque con lentitud, se ha ido avanzando, poco a poco.

Dar cuenta de los principales cambios que ha impuesto el proceso de ajuste del ordenamiento español al régimen comunitario de las ayudas de Estado, es precisamente el objeto principal de estas páginas. Aunque antes conviene recordar, siquiera sea de manera sucinta, los rasgos generales de ese régimen.

\section{PRINCIPALES CARACTERÍSTICAS DEL RÉGIMEN COMUNITARIO DE LAS AYUdAS De Estado}

El artículo 107.1 TFUE establece que «salvo que el presente Tratado disponga otra cosa, serán incompatibles con el mercado común, en la medida en que afecten a los intercambios comerciales entre Estados miembros, las ayudas otorgadas por los Estados o mediante fondos estatales, bajo cualquier forma, que falseen o amenacen falsear la competencia, favoreciendo a determinadas empresas o producciones». La incompatibilidad queda referida, como punto de partida, a toda ayuda prevista y otorgada por un poder público — cualquiera que sea la autoridad nacional que adopte la decisión-y dicha ayuda ha de traducirse en una transferencia de fondos públicos con independencia de la for-

se citarán más adelante, baste ahora con la siguiente muestra de monografías, dejando al margen artículos y comentarios jurisprudenciales: L. FERnÁNDEZ DE LA GÁNDARA y A. L. CALVO CARAVACA (1991), Las ayudas de Estado en la Comunidad Económica Europea, Murcia: Comunidad Autónoma de Murcia, Secretaría General de la Presidencia; A. Valle Gálvez (1993), «Las ayudas de Estado en la jurisprudencia del Tribunal de Justicia de las Comunidades Europeas», en El Derecho Comunitario Europeo y su aplicación judicial (págs. 885 y ss.), Madrid: Civitas; G. Fernández Farreres (1993), El régimen de las ayudas estatales en la Comunidad Europea, Madrid: Civitas; L. Arpio Santacruz (2000), Las ayudas públicas ante el Derecho Europeo de la Competencia, Pamplona: Aranzadi; E. García-Trevijano Garnica (2002), Los procedimientos comunitarios de control de ayudas de Estado, Madrid: Civitas; A. Estoa Pérez (2006), El control de las ayudas de Estado, Madrid: Iustel; J. L. Buendía Sierra y S. Cabrera Zaragoza (2008), «El control de las ayudas de Estado y la nueva Ley de Defensa de la Competencia», en La Ley 15/2007 de Defensa de la Competencia. Jornada de Estudio de la Asociación Española de Defensa de la Competencia, Madrid: La Ley; J. A. Rodríguez Míguez (2009), "Control de ayudas públicas», en Derecho de la libre competencia comunitario y español, Cizur Menor: Thomson Aranzadi. 
ma en que se realice, equiparándose a la misma los supuestos en los que la correspondiente autoridad pública renuncia a fondos que le corresponden o hubieran podido corresponder (caso paradigmático, los beneficios fiscales en sus diferentes modalidades). La incompatibilidad queda referida, por tanto, a cualesquiera ayudas, englobándose en esa categoría, tal como viene repitiendo de manera constante la jurisprudencia comunitaria, no sólo prestaciones positivas, como las propias subvenciones, sino también intervenciones que, bajo diversas formas, aligeran las cargas que normalmente pesan sobre el presupuesto de una empresa y que, por ello, sin ser subvenciones en el sentido estricto de la palabra, tienen la misma naturaleza e idénticos efectos. Se adopta, en consecuencia, un criterio muy amplio de ayuda, al englobar muy diversos supuestos, razón por la cual este concepto comunitario de ayuda no es totalmente equiparable al de subvención que sanciona nuestro ordenamiento jurídico (artículo 1 de la Ley General de Subvenciones de 2003) $)^{3}$.

A partir de aquí, la ayuda incompatible se ha de traducir, en primer lugar, en una ventaja económica para las empresas. Y para determinar la existencia de este requisito hay que tener en cuenta: que la ayuda debe beneficiar económicamente a una o varias empresas y el concepto de empresa se interpreta a estos efectos en términos muy amplios ${ }^{4}$; que la ayuda ha de suponer una ventaja económica que no se habría obtenido en condiciones normales de mercado, de manera que, aun cuando pueda haber contraprestación de la beneficiaria, lo trascendental es que se materialice una ventaja económica ${ }^{5}$ y para determinar si existe ventaja económica cuando la beneficiaria es una empresa pública, se viene utilizando el criterio del "inversor privado", lo que equivale a decir que el Estado ninguna ayuda otorga si actúa de la misma forma en que lo haría un inversor privado en condiciones de mercado 6 .

3 En consecuencia, desde la perspectiva comunitaria, toda subvención es calificable como ayuda de Estado, pero, desde la perspectiva nacional, no toda ayuda de Estado será necesariamente una subvención. Lo que, como veremos, no deja de ser relevante en relación con la efectiva ejecución de las decisiones de las autoridades comunitarias sobre la compatibilidad de tales ayudas con el mercado común europeo.

4 En concreto, se considera como empresa toda entidad que ejerza una actividad económica consistente en ofrecer bienes y servicios en un determinado mercado, con independencia de su forma jurídica y de su financiación, por lo que alcanza tanto a una sociedad como a una asociación, a cualquier otra organización distinta sin ánimo de lucro, e incluso a un trabajador autónomo. Y, desde luego, con independencia de su titularidad pública o privada.

5 Por eso puede ser calificada como ayuda, por ejemplo, la medida en virtud de la cual una empresa recibe un servicio del Estado a un precio inferior del mercado.

6 No obstante, el significado de este criterio del «inversor privado» es tan sencillo de formular como difícil de aplicar. Determinar si el Estado, al adoptar la medida de ayuda, actúa como lo haría un inversor normal, racional, prudente, es una tarea compleja que inevitablemente conlleva un amplio margen de apreciación. 
La ayuda, además, ha de ser selectiva, considerándose que lo es cuando beneficia a unas empresas y no a otras que, sin embargo, se encuentran en la misma situación o en competencia, alterándose, en consecuencia, el equilibrio entre ellas. Y para concretar debidamente el alcance de este nuevo requisito se debe tener en cuenta: que no habrá ayuda cuando el Estado adopta medidas de carácter general de política económica, fiscal o social que se dirigen a todas las empresas de un Estado de forma objetiva, repercutiendo sobre varios sectores y aplicándose por igual en todo el territorio nacional ${ }^{7}$; que la determinación del carácter selectivo de la medida debe realizarse atendiendo a quiénes sean los beneficiarios de la misma, habiéndose considerado, por ejemplo, que son selectivas las medidas que benefician a empresas de concretas regiones, de determinados sectores o de determinada clase; asimismo, que la medida será selectiva cuando constituya una excepción en el sistema general en el que se enmarca, aunque no haya competidores discriminados en el territorio en cuestión; y que, en todo caso, la selectividad de algunas medidas fiscales puede estar justificada por la naturaleza o la economía del sistema, de manera que, aunque supongan una ventaja, no podrán calificarse como ayuda de Estado ${ }^{8}$.

Por último, la ayuda ha de incidir en la competencia y los intercambios comerciales, considerando la jurisprudencia que ambas condiciones están inseparablemente unidas y que se presumirá la incidencia cuando la beneficiaria de la ayuda sea una empresa que opera en un sector abierto a la competencia con dimensión comunitaria, siendo indiferente, incluso, que la beneficiaria opere sólo a escala local o no participe en las exportaciones o exporte sólo a terceros países. En todo caso, no es necesario acreditar la incidencia real de la ayuda en los intercambios comerciales entre los Estados miembros y en la competencia, sino que de lo que se trata es de determinar la posible afectación de dichos intercambios. Y, por otra parte, dado que el sector económico en el que actúa la empresa beneficiaria debe estar abierto a otros competidores, nada se falseará cuando no haya competencia en el mismo9 ${ }^{9}$. Así pues, se parte de un criterio muy amplio, ya que los efectos sobre la competencia y los

\footnotetext{
${ }^{7}$ Es el caso de medidas, por ejemplo, que tratan de favorecer al conjunto de la economía, como sucede con la mayoría de las establecidas en materia de empleo y formación, que suelen tener carácter general.

${ }^{8}$ Quiere decirse, por ejemplo, que la selectividad derivada de todo impuesto progresivo quedará justificada si el mismo pretende simplemente la redistribución de la riqueza, aunque de todas formas, esa justificación no podrá hacerse sino caso por caso.

${ }^{9}$ No otra cosa sucederá, por ejemplo, en servicios adjudicados con carácter exclusivo a una empresa, ya que no existe competencia potencial. Sin embargo, la ayuda a una empresa de un sector no liberalizado podrá considerarse que falsea la competencia si la empresa también opera en sectores liberalizados.
} 
intercambios no tienen porqué ser sustanciales y, además, porque resulta irrelevante la finalidad de la ayuda, ya que sólo se define en función de sus efectos ${ }^{10}$.

Delimitado el concepto de ayuda incompatible con el mercado común en los términos señalados, el artículo 107.2 TFUE excepciona de la incompatibilidad o prohibición a tres tipos de ayudas de Estado ${ }^{11}$, por lo que, en tanto que la ayuda se pueda subsumir en alguno de ellos, la Comisión deberá autorizarla, sin disponer de margen alguno de valoración, de manera que bien puede afirmarse que son excepciones objetivas a la regla de la incompatibilidad. Pero junto a estas ayudas compatibles ex lege, el apartado 3 del mismo artículo 107 prevé otras clases de ayudas que «podrán ser declaradas compatibles» cuando la Comisión considere que sus beneficios son superiores al falseamiento que pueden producir en la competencia y el mercado ${ }^{12}$. En consecuencia, la determinación de si una medida constituye una ayuda de Estado y si, aun siendo calificable como tal, puede acogerse a alguna de las excepciones previstas, corresponde a la Comisión, sin perjuicio de la fiscalización última de los órganos jurisdiccionales comunitarios y de las competencias que al Consejo le reconoce el artículo 108.2, párrafo $3^{\circ}$, TFUE. Y a tal fin, la Comisión ha de seguir un determinado procedimiento, que, regulado por el Reglamento CE 659/1999, del Consejo, de 22 de marzo, por el que se establecieron las reglas de aplicación del artículo 93 TCE (actual artículo 108 TFUE) y modificado por el Reglamento UE 734/2013, del Consejo, de 22 de julio, en lo más destacado, se caracteriza por las siguientes notas.

En primer lugar, el Estado miembro interesado debe notificar a la Comisión a su debido tiempo cualquier proyecto de concesión de nue-

10 Tanto es así que no importa que los competidores también reciban ayudas de Estado, ni tampoco importa que el mercado sea poco competitivo, o que, como ya hemos dicho, la empresa sólo opere localmente, etc.

11 Concretamente, las ayudas sociales a consumidores individuales, las ayudas destinadas a reparar perjuicios causados por desastres naturales o acontecimientos de carácter excepcional, y las ayudas con el objeto de favorecer la economía de determinadas regiones de la República Federal de Alemania afectadas por la división de Alemania, siempre que sean necesarias para compensar las desventajas económicas derivadas de la división.

12 Se ha de tratar de ayudas destinadas a favorecer el desarrollo económico de regiones en las que el nivel de vida sea anormalmente bajo o en las que exista una grave situación de subempleo, o de ayudas para fomentar la realización de un proyecto importante de interés común europeo o destinadas a poner remedio a una grave perturbación en la economía de un Estado miembro, o de ayudas destinadas a facilitar el desarrollo de determinadas actividades o de determinadas regiones económicas, siempre que no alteren las condiciones de los intercambios en forma contraria al interés común, o de ayudas destinadas a promover la cultura y la conservación del patrimonio, cuando no alteren las condiciones de los intercambios y de la competencia en la Comunidad en contra del interés común, o, en fin, de cualesquiera otras categorías de ayudas que determine el Consejo por decisión tomada por mayoría cualificada, a propuesta de la Comisión. 
va ayuda y debe presentar toda la información necesaria para que la Comisión pueda tomar una decisión, aunque las ayudas de Estado de poca cuantía quedan exentas de la obligación de notificación, al haberse establecido un límite máximo por debajo del cual las ayudas escapan del ámbito de aplicación del artículo 107.1 TFUE ${ }^{13}$. De este modo, las ayudas que se han de notificar sólo se pueden hacer efectivas si la Comisión adopta, o se considera que ha adoptado, una decisión que las autoriza, rigiendo, por tanto, la llamada cláusula de suspensión. Por lo demás, la notificación debe efectuarse por medio de un formulario de notificación que se ha de transmitir electrónicamente.

Recibida la comunicación, si la Comisión considera que la medida notificada plantea dudas sobre su compatibilidad con el mercado único, incoará un procedimiento de investigación formal de la ayuda proyectada. Esta decisión deberá resumir las principales cuestiones de hecho y de derecho, incluirá una valoración inicial de la medida propuesta y expondrá las razones que hacen dudar de su compatibilidad. Frente a la misma, el Estado miembro afectado y las partes interesadas podrán presentar sus observaciones en un plazo no superior a un mes, a no ser que la Comisión lo prorrogue, y el procedimiento de investigación concluirá con una decisión que declarará: o que la medida notificada no es constitutiva de ayuda; o que las dudas se han disipado y se considera que la ayuda es compatible (decisión positiva, que, de todas formas, puede estar acompañada de condiciones y obligaciones que permitan asegurar la compatibilidad, en cuyo caso se califica como decisión condicional); $\mathrm{o}$, en fin, que la medida notificada es sencillamente incompatible con el mercado común y no puede ejecutarse (decisión negativa). Y si el Estado miembro no se conforma con la decisión condicional o negativa, la Comisión puede recurrir directamente al Tribunal de Justicia.

Por otra parte, cuando obre en poder de la Comisión información referente a una presunta ayuda ilegal (es decir, una ayuda puesta en práctica sin observancia de la obligación de notificación previa a la Co-

13 Estas ayudas denominadas de mínimis se establecieron inicialmente por una Comunicación de la Comisión de 1996, y posteriormente se regularon por el Reglamento CE 61/2001, y por el Reglamento CE 1998/2006, de la Comisión, de 15 de diciembre de 2006, que multiplicó por dos la cuantía de las ayudas hasta ese momento exentas de la referida notificación y control y, además, amplió su ámbito de aplicación. Y, en la actualidad, de acuerdo con el Reglamento UE 1407/2013, de la Comisión, de 18 de diciembre, las ayudas concedidas durante un período de tres años que no excedan del límite máximo de 200.000 euros no se consideran ayudas estatales, si bien para el sector del transporte de mercancías por carretera se fija el límite máximo de 100.000 euros y siempre que la ayuda no lo sea para la adquisición de vehículos (y ello por razón, fundamentalmente, del exceso de capacidad del sector y la congestión de las carreteras). En todo caso, el mismo Reglamento dispone que los Estados miembros deben dotarse de instrumentos adecuados que garanticen que el importe total de las ayudas de mínimis concedidas a una única empresa no sea superior al máximo permisible. 
misión), cualquiera que sea la fuente de información (aunque normalmente mediará denuncia), la Comisión procederá a su examen sin demora, pudiendo solicitar del Estado miembro en cuestión que le facilite más información. La Comisión, tras ofrecer al Estado la oportunidad de presentar sus observaciones, podrá adoptar una decisión por la que se le ordene suspender la concesión de la ayuda ilegal, o también la recuperación provisional de las que ya hubiere otorgado, hasta el momento en que se adopte un pronunciamiento sobre su compatibilidad con el mercado común. La orden de recuperación queda condicionada, no obstante, a que, según una práctica establecida, el carácter de ayuda de la medida en cuestión no deje lugar a dudas, a que haya urgencia de actuar y a que exista un riesgo inminente de perjuicio sustancial e irrevocable para un competidor. Y también en este supuesto, de no conformarse el Estado miembro con la decisión cautelar adoptada, la Comisión podrá plantear el caso directamente ante el Tribunal de Justicia para que determine si el incumplimiento del Estado constituye o no una violación del Tratado.

Tramitado el procedimiento, de alcanzarse una decisión negativa respecto de la ayuda ilegal, la Comisión obligará al Estado en cuestión a adoptar todas las medidas necesarias para lograr que el beneficiario devuelva la ayuda (lo que se conoce como decisión de recuperación). Una recuperación de la ayuda que sólo se puede excepcionar cuando la misma pudiera suponer la violación de un principio general del derecho europeo, como es el caso de los principios de protección de la confianza legítima ${ }^{14}$ y de seguridad jurídica. Lo cual, de todas formas, también puede desembocar en un pronunciamiento del Tribunal de Justicia.

Por último, la Comisión puede exigir de los Estados toda la información necesaria para proceder al examen de los regímenes de ayudas existentes, examen que se realizará en cooperación con el correspondiente Estado. Y si la Comisión llega a la conclusión de que un régimen de ayudas ha dejado de ser compatible con el mercado común, remitirá al Estado una recomendación en la que le propondrá una modificación de fondo del régimen de ayudas o, sin más, su supresión. Además, los Estados deben presentar a la Comisión un informe anual sobre todos los regímenes de ayudas existentes, en formato electrónico y a más tardar el

14 Conviene recordar que el principio de protección de la confianza legítima es de aplicación cuando una actuación de la Comisión, o de cualquier otro órgano comunitario competente, hubiera dado esperanzas justificadas a las autoridades nacionales o a los beneficiarios de las ayudas de que las mismas eran legales, aunque, en principio, según la jurisprudencia del Tribunal de Justicia, a no ser que concurran circunstancias excepcionales, difícilmente puede reconocerse confianza legítima si el Estado ha incumplido la obligación de notificar previamente a la Comisión. 
30 de junio del año en curso. Y, desde la perspectiva ahora de la colaboración entre la Comisión y los órganos jurisdiccionales nacionales, éstos pueden solicitar a aquélla información o dictámenes sobre aspectos concretos de la aplicación de las normas sobre ayudas de Estado. Simultáneamente, también se ha previsto que la Comisión tenga la facultad de personarse ante los órganos jurisdiccionales para presentar observaciones escritas e, incluso, orales, cuando dichos órganos conozcan de asuntos en los que tengan que aplicar el artículo 107.1 o el artículo 108 del TFUE ${ }^{15}$.

Hasta aquí, en sus rasgos generales, la regulación material y procedimental al servicio del control comunitario de las ayudas de Estado. Una regulación que, como fácilmente se comprende, posibilita que las decisiones sobre la compatibilidad de las ayudas estén fuertemente condicionadas por criterios político-económicos, en función de las circunstancias económicas de cada momento. Un dato que la actual crisis económica ha puesto abiertamente de manifiesto, al graduarse la intensidad del control en función de la magnitud y relevancia de los efectos «anticrisis» que de las ayudas puedan esperarse. No estamos en presencia, por tanto, de un control meramente formal. Y por eso mismo, aunque el análisis de los efectos económicos que las ayudas previstas puedan desplegar se trata de presentar como un criterio estrictamente técnico, en el fondo ese análisis no deja de ser trasunto de una previa opción político-económica. La práctica seguida en los últimos años así lo acredita. Bien puede suscribirse por ello la afirmación de que en materia de ayudas la crisis ha llevado a que la Comisión, más que «guardiana de la competencia, supraordenada a los Estados», ha pasado a ser sobre todo «la coordinadora de los programas anticrisis de los Estados miembros» 16 .

Es claro, por tanto, que el derecho europeo de las ayudas de Estado no tiene por objetivo la erradicación sin más de tales ayudas, como bien lo prueba, por lo demás, el que las propias autoridades comunitarias nunca hayan renunciado a su uso frente a terceros, especialmen-

${ }^{15}$ Sin perjuicio de lo que más adelante se dice, debe tenerse en cuenta que las jurisdicciones nacionales no tienen competencia para determinar por sí mismas si una determinada ayuda es compatible o no con el mercado europeo, ya que ese juicio corresponde a la Comisión con el ulterior control del Tribunal de Justicia. Pero no es menos cierto que las jurisdicciones nacionales sí pueden controlar tanto las ayudas ilegales (es decir, las que se han otorgado sin observancia de la obligación de comunicación previa a la Comisión) como las ayudas sujetas a determinados requisitos de otorgamiento previstos por los Reglamentos de exención para determinadas categorías de ayudas, de acuerdo con lo dispuesto por el Reglamento 994 de 1998, del Consejo. De manera que, en estos casos, queda abierta la posibilidad de que en el correspondiente proceso pueda personarse la Comisión.

16 M. FHeling (2010), «La reacción de los Estados europeos frente a la crisis y el Derecho europeo de ayudas públicas», El Cronista, 11, págs. 6 y ss. 
te como mecanismos de protección de determinadas producciones comunitarias ${ }^{17}$. En realidad, la finalidad es otra. Sencillamente, la de que las instancias comunitarias controlen el uso que de las mismas hacen los Estados. Y es que no puede perderse de vista que las ayudas públicas económico-financieras, en sus distintas formas y variantes, son un medio característico y habitual de intervención que, además, ocupa un lugar preeminente, no sólo por la magnitud que ha alcanzado el gasto público destinado al desarrollo de este tipo de acciones, sino por su propia significación cualitativa en el marco general de las políticas públicas.

En definitiva, los hechos evidencian que no hay valores absolutos en esta materia. Aunque se reconoce que las ayudas estatales erosionan la libertad de competencia al interferir en el empleo eficiente de los recursos y en los intercambios comerciales, razón por la cual deberían ser suprimidas o, al menos, restringidas a supuestos excepcionales ${ }^{18}$, al final todos estos postulados quedan fuertemente relativizados. Las prácticas comunitarias seguidas avalan que las ayudas se consideran necesarias y hasta imprescindibles, máxime cuando el sistema económico en su conjunto, o sectores del mismo especialmente sensibles, entran en crisis.

\section{LA ADECUACIÓN DEL ORDENAMIENTO JURÍDICO ESPAÑOL AL RÉGIMEN COMUNITARIO DE LAS AYUdAS DE ESTADO}

Dadas las limitaciones de extensión a las que necesariamente tiene que ajustarse esta colaboración, y, por tanto, dejando al margen otras cuestiones no menos importantes ${ }^{19}$, conviene fijar seguidamente la

17 De ahí los continuos intentos del sistema GATT-OMC para incorporar de manera progresiva límites más estrictos a la utilización de estos instrumentos proteccionistas. Un análisis de la regulación del referido sistema en I. DE LA Riva (2004), Ayudas Públicas, Buenos Aires: Depalma.

18 Debe recordarse que la actividad subvencional siempre ha estado sujeta a severas críticas. Se ha dicho que falsean el funcionamiento del mercado, permitiendo sobrevivir a producciones marginales que en condiciones de mercado normales desaparecerían. Se ha advertido, igualmente, que las subvenciones operan como mecanismos de socialización de pérdidas, con lo que queda afectada la esencia misma del sistema de economía de mercado, presidido por el principio de libre competencia. También, que concurren graves problemas adherentes a la incidencia de las subvenciones en el sistema económico, ya que no puede determinarse con exactitud la importancia y la utilidad final de las ayudas para los beneficiarios y para la economía nacional en su conjunto. Por lo demás, no son críticas de ahora, como ya reflejé en mi libro (1983) La subvención: concepto y régimen jurídico, Madrid: IEF. Tampoco lo son las que, desde una perspectiva más general, han advertido del peligro que encierran para la propia democracia, según cual sea la finalidad y destino que se les dé. Sin embargo, como es notorio, esas críticas y advertencias no han impedido que los poderes públicos sigan haciendo un uso intenso de las mismas.

19 Como dar cuenta, por ejemplo, de los numerosos asuntos en los que se ha visto implicado y condenado el Reino de España, tanto por establecer y otorgar ayudas contrarias al dere- 
atención en las medidas que ha sido preciso adoptar para ajustar el ordenamiento jurídico español al régimen comunitario de las ayudas de Estado. Aunque no todas puedan ser referidas en esta breve crónica, al menos conviene resaltar las siguientes.

Ante todo, debe destacarse la relativa a los mecanismos internos necesarios para hacer efectiva las declaraciones de ilegalidad que conlleven la obligación de recuperar las ayudas otorgadas. Una recuperación que, como dispone el artículo 14.3 del Reglamento comunitario 659/1999, «se efectuará sin dilación y con arreglo a los procedimientos del derecho nacional del Estado miembro interesado, siempre que permitan la ejecución inmediata y efectiva de la decisión de la Comisión». Y es que, hasta no hace muchos años, el derecho español no dispuso de instrumentos eficaces y expeditivos para hacer efectiva dicha obligación. La deficiencia finalmente se ha corregido, si bien aún se plantean algunas dificultades que deben solventarse procediendo a una interpretación y aplicación de las normas previstas conforme a los imperativos comunitarios $^{20}$.

En efecto, la Ley 38/2003, de 17 de noviembre, General de Subvenciones, y su Reglamento aprobado por Real Decreto 887/2006, de 21 de julio, han atendido directa y expresamente a esta cuestión, al prever un procedimiento de reintegro de las cantidades percibidas, incluida la exigencia del interés de demora desde el momento de su pago o entrega, cuando

cho de la Unión como por incumplir la subsiguiente obligación de recuperación. Baste recordar ahora dos de gran notoriedad. En concreto, el asunto de las vacaciones fiscales vascas, que, finalmente, tras no pocos requerimientos e incidencias procedimentales, llevó a la Comisión a recurrir ante el TJUE el incumplimiento por parte de España de la obligación de recuperar las ayudas fiscales adoptadas por los territorios forales de Álava, Guipúzcoa y Vizcaya que fueron denunciadas por la Comisión ante el TJUE y que la Sentencia de 14 de diciembre de 2006 declaró que debían ser consideradas ayudas de Estado contrarias al DUE, siendo desestimados por la Sentencia de 9 de junio de 2011 los recursos de casación que contra la misma interpusieron los señalados territorios forales. Y más recientemente, el asunto no menos importante del régimen fiscal aplicable a determinados acuerdos del arrendamiento financiero de buques, sobre el que se pronunció la Comisión en su decisión de 17 de julio de 2013, considerando que se trataba de una ayuda de Estado incompatible e ilegal, pero que la Sentencia del Tribunal General de 17 de diciembre de 2015 ha anulado, sin perjuicio de que el asunto no esté definitivamente resuelto, ya que la misma ha sido recurrida.

${ }^{20}$ La cuestión ha tenido amplio reflejo y tratamiento en la doctrina. Entre otros, vid. J. R. Fernández Torres (1991), «La revisión de oficio de los actos dictados con infracción del Derecho Comunitario», Revista de Administración Pública, 125, págs. 281 ss. y (2003), "La recuperación de las ayudas de Estado, una exigencia de difícil cumplimiento», en Estudios de Derecho Público Económico. Libro homenaje al profesor Sebastián Martín-Retortillo (págs. 779 y ss.), Madrid: Civitas; M. Rebollo Puig (2005), «El reintegro de subvenciones», en G. FERnÁndeZ Farreres (dir.), Comentario a la Ley General de Subvenciones (págs. 407 y ss.), Madrid: Civitas; L. A. Martínez Giner (2006), El reintegro de subvenciones públicas, Madrid: Iustel; J. García LuEngo (2010), El reintegro de subvenciones, Cuadernos Civitas, Madrid: Thomson Reuters; A. Bueno Armijo (2011), El reintegro de subvenciones de la Unión Europea, Sevilla: IAAP; X. Arzoz Santisteban (2013), Revisión de actos administrativos nacionales en Derecho Administrativo Europeo, Madrid: IVAP-Civitas. 
concurran diversas causas. Entre las mismas, el artículo 37.1.h) de la citada Ley prevé la siguiente: «La adopción, en virtud de lo establecido en los artículos 87 a 89 del Tratado de la Unión Europea, de una decisión de la cual se derive una necesidad de reintegro». La relevancia práctica de esta previsión es notable. Y es que, con arreglo a la misma, el reintegro (o devolución de las cantidades percibidas) no requiere ya de la previa declaración de nulidad del acto de otorgamiento a través del procedimiento de revisión de oficio de los actos nulos (artículo 102 de la Ley 30/1992, de 26 de noviembre, de Régimen Jurídico de las Administraciones Públicas y del Procedimiento Administrativo Común), ni, en su caso, de la declaración judicial, en virtud de sentencia, de la disconformidad del acto con el ordenamiento jurídico, a instancia de la propia Administración autora del acto y tras la declaración de lesividad del mismo (artículo 103 de la misma Ley 30/1992, de 26 de noviembre).

Así pues, el precepto legal evita tener que acudir a los procedimientos internos de revisión de oficio o de lesividad e impugnación ante los tribunales contencioso-administrativos para hacer efectiva la decisión comunitaria que, declarando la incompatibilidad de la ayuda de Estado, conlleve la obligación de proceder a su inmediata recuperación. Y ello porque tal decisión equivale sencillamente a un efectivo título ejecutivo que permite poner en marcha sin más el procedimiento de reintegro. Si con anterioridad no era título ejecutivo (lo que obligaba a anular el acto, a través de los procedimientos de revisión en vía administrativa previamente a iniciar el procedimiento de reintegro), ahora, por imperativo legal, opera como si lo fuera. De este modo, atendiendo a sus resultados prácticos, bien puede afirmarse que la decisión comunitaria que deviene firme y consentida equivale o se equipara de facto a la revocación o anulación del acto de la autoridad nacional que otorgó la ayuda, de manera que la Administración correspondiente deberá proceder sin más a exigir del beneficiario el reintegro de la cantidad percibida y éste a reintegrarla más los intereses de demora. El cambio, por tanto, ha sido sustancial y acertado, lo que no ha dejado de destacarse por el propio Consejo de Estado en su «Informe sobre la inserción del derecho europeo en el ordenamiento español», de 14 de febrero de $2008^{21}$.

21 Dice así, en págs. 229-230: «En consecuencia, el legislador descarta reputar nula la ayuda de Estado contraria al derecho comunitario, pero impone su devolución, remitiendo a preceptos del Tratado constitutivo de la Comunidad Europea [en la actualidad, Tratado de Funcionamiento de la Unión Europea] — y no del de la Unión Europea, como se dice literalmente- en cuanto al régimen sustantivo del que ha de derivarse la necesidad de reintegro. En resumen, desde que desapareciera la revisión de oficio en vía administrativa de actos declarativos de derecho anulables, ha sido una preocupación del Consejo de Estado la inexistencia de mecanismos apropiados para expulsar de la realidad jurídica los actos firmes declarados contrarios al derecho comunitario, especialmente en el caso de las ayudas de Estado incompatibles con el 
Ahora bien, obsérvese que la causa de reintegro que nos ocupa queda referida formalmente a las subvenciones stricto sensu, tal como quedan delimitadas por el artículo 1 de la Ley General de Subvenciones de 2003, por lo que de inmediato surge la duda de si alcanza también a las ayudas que no adopten la forma de subvención ${ }^{22}$. Un problema que no parece admitir otra solución que no pase por recurrir a una interpretación del criterio legal establecido conforme al derecho de la Unión, lo que significa que también cabrá hacer uso del procedimiento de reintegro.

En suma, lo verdaderamente relevante es que, como expresamente dispone el artículo 41.2 de la misma Ley General de Subvenciones, si el reintegro se exige con base a acuerdos de órganos de la Unión Europea, el órgano nacional «ejecutará dichos acuerdos». Es decir, que no cabe discutir la procedencia del reintegro cuando el mismo se deba a una decisión comunitaria. El reintegro viene impuesto por ésta, sin más, lo que obliga a su inmediata ejecución. De manera que, este caso, la observancia del procedimiento no tiene otra finalidad que la de verificar la existencia misma de la decisión comunitaria y, si hubiere lugar a ello, la fijación de la cuantía que deba reintegrarse.

Pero si la cuestión ha sido resuelta de manera tan expeditiva, con notable pragmatismo, aún queda por dar respuesta a la cuestión de cómo se garantiza por el Estado que, siempre de acuerdo con las reglas que se acaban de referir, la Administración competente para procurar el reintegro (en particular, cuando se trate de las Administraciones autonómicas o de las Administraciones locales, por haber sido las otorgantes y a ellas corresponderles la ejecución con arreglo al sistema interno o nacional de distribución de competencias) lo haga de manera efectiva, incoando el procedimiento debido frente al beneficiario de la ayuda declarada ilegal o incompatible con el derecho de la Unión.

mercado común. Dicha preocupación se ha desvanecido en este contexto concreto, al haberse previsto un procedimiento de reintegro para tales ayudas en la Ley 38/2003, de 17 de noviembre, General de Subvenciones, si bien pervive para otros casos en los que se declare igualmente la infracción del derecho comunitario por un acto favorable determinado».

${ }^{22}$ Para aclarar este importante extremo, debe recordarse que la Ley General de Subvenciones «tiene por objeto la regulación del régimen jurídico general de las subvenciones otorgadas por las Administraciones Públicas» (artículo 1), considerando como subvención, a los efectos de la misma, «toda disposición dineraria realizada por cualesquiera de los sujetos contemplados en el artículo 3 de esta Ley, a favor de personas públicas o privadas, y que cumpla los siguientes requisitos: a) Que la entrega se realice sin contraprestación directa de los beneficiarios; b) Que la entrega esté sujeta al cumplimiento de un determinado objetivo, la ejecución de un proyecto, la realización de una actividad, la adopción de un comportamiento singular, ya realizados o por desarrollar, o la concurrencia de una situación, debiendo el beneficiario cumplir las obligaciones materiales y formales que se hubieran establecido; [y] c) Que el proyecto, la acción, conducta o situación financiada tenga por objeto el fomento de una actividad de utilidad pública o interés social o de una promoción de una finalidad pública». 
Es lógico esperar que, atendiendo al automatismo e inmediatez con que se configura el reintegro, el órgano al que corresponda la ejecución procederá sin más al mismo. Justamente en ello radica el avance que se ha producido, al facilitar la ejecución en los términos señalados. Sin embargo, no es menos cierto que el incumplimiento siempre es posible y de ahí que deban preverse medidas de reacción últimas por parte de las autoridades centrales, que a la postre son las que asumen la responsabilidad frente a los órganos comunitarios.

Pues bien, conviene recordar que se ha previsto recientemente un mecanismo último, a modo de cierre del sistema de cumplimiento del derecho de la Unión y de las decisiones firmes de los órganos comunitarios, que compele a las autoridades autonómicas y locales a su pronta y rápida ejecución, dadas las consecuencias de orden patrimonial que, en otro caso, de su no acción o deficiente acción, para ellas mismas se derivarán. Y es que el Estado (recuérdese, único y exclusivo responsable del cumplimiento ante los órganos comunitarios) puede repercutir en la correspondiente Comunidad Autónoma o Administración local las consecuencias derivadas de la responsabilidad por inobservancia de las obligaciones comunitarias. La disposición adicional primera de la Ley 2/2011, de 4 de marzo, de Economía Sostenible, vino a establecer, con carácter general, que el Estado repercutirá las sanciones pecuniarias que le sean impuestas por incumplimientos imputables a las comunidades autónomas o a las entidades locales. Y posteriormente, la Ley Orgánica 2/2012, de 27 de abril, de Estabilidad Presupuestaria, ha elevado a rango de ley orgánica el referido precepto. Estamos, pues, ciertamente, ante un paliativo, por cuanto, más allá de que esa responsabilidad se repercuta en el efectivo causante del incumplimiento, lo cierto es que con ello no se evita el daño o perjuicio para el Estado en su conjunto. Sin embargo, tampoco puede discutirse que, en última instancia, es un remedio necesario y eficaz.

Aún debe añadirse que esta repercusión de la responsabilidad comunitaria del Estado lo será, de todas formas, en la parte que corresponda, lo que exige tener en cuenta no sólo el sistema de distribución de competencias entre las diversas instancias territoriales, sino también la competencia que para la garantía del cumplimiento del derecho de la Unión Europea corresponde al Estado. Una garantía que puede llevar a que, aun cuando lo sea en contadas ocasiones, la repercusión interna de la responsabilidad tenga que ser compartida por el Estado ${ }^{23}$.

23 He examinado esta cuestión en mi trabajo (2015), «La repercusión sobre las Comunidades Autónomas de la responsabilidad del Estado por incumplimiento del Derecho de la Unión Europea», Revista Española de la Función Consultiva, 15, págs. 44 y ss. 
Por otra parte, deben tenerse en cuenta también los supuestos de reintegro de subvenciones financiadas con cargo a fondos comunitarios, que igualmente han planteado problemas, sobre todo en los casos de subvenciones que, aun siendo financiadas por dichos órganos, a las Administraciones nacionales corresponde su tramitación y ejecución (caso de los pagos realizados en el marco de la PAC y en la mayoría de los instrumentos financieros comunitarios de política estructural: FEDER, FSE, IFOP, etc.). Unos problemas, sin embargo, que, en gran medida, la misma Ley General de Subvenciones ha solventado de nuevo con gran pragmatismo, al dar entrada al mismo régimen de reintegro en cumplimiento de la exigencia comunitaria de que «los Estados miembros adoptarán para combatir el fraude que afecte a los intereses financieros de la Comunidad las mismas medidas que para combatir el fraude que afecte a sus propios intereses financieros» (artículo 325 TFUE).

Distinta es, por el contrario, la valoración que ha de merecer la falta de un adecuado sistema de control interno o nacional de la compatibilidad de las ayudas con el derecho de la competencia. La resistencia del legislador a establecer un mecanismo de control interno, a nivel nacional, operativo y eficaz, es clamorosa, lo que supone que la única posibilidad de defensa de los competidores de las empresas beneficiarias de subvenciones y ayudas pase por reclamar la intervención de la Comisión Europea. Baste decir a este respecto que, si con arreglo a la vieja Ley de 30 de julio de 1963, de represión de prácticas restrictivas de la competencia, las ayudas públicas quedaron al margen de la esfera de intervención del Tribunal de Defensa de la Competencia, con la Ley 16/1989, de 17 de julio, de Defensa de la Competencia, en un contexto ya radicalmente distinto, poco se mejoró. Simplemente por guardar las apariencias, el artículo 19 de dicha ley previó la posibilidad de que el tribunal examinase y se pronunciase acerca de la incidencia de las ayudas sobre las condiciones de competencia cuando así fuese requerido por el ministro de Economía y Hacienda, sin que, por lo demás, su dictamen llegase a ser vinculante, sirviendo exclusivamente para que el mismo ministro pudiera proponer a los poderes públicos, si así lo estimara pertinente, la suspensión o la modificación de las ayudas y la adopción de las medidas conducentes al mantenimiento o al restablecimiento de la competencia. Una regulación, por tanto, manifiestamente insuficiente y en verdad criticable, que, por lo demás, el artículo 11 de la nueva Ley 15/2007, de 3 de julio, de Defensa de la Competencia, aunque en algo la haya corregido, no lo ha hecho en la medida necesaria. De manera que la autoridad nacional encargada específicamente de la defensa de la competencia bien poco puede hacer 
frente a aquellas ayudas que afectan al normal desenvolvimiento del mercado ${ }^{24}$.

Por último, no puede concluir este breve repaso a algunos de los reajustes que ha impuesto el régimen de las ayudas de Estado sin una mención al papel que cumple desarrollar a los órganos jurisdiccionales en el control de tales ayudas. Y es que los tribunales nacionales no pueden pronunciarse, ciertamente, sobre la compatibilidad de las ayudas con el mercado común, pero sí pueden controlar las que sean ilegales, que son las otorgadas con infracción del procedimiento de control comunitario y con independencia, por tanto, de su compatibilidad por razones de fondo, tal como desde hace tiempo ha establecido la jurisprudencia comunitaria (baste remitir a la STJCE 21 de noviembre de 1991, as. C-354, Rec. 1990, p. I-5505, y conclusiones del abogado general Jacobs).

Con todo, tampoco han dejado de plantearse dificultades. Así, a los efectos de aplicar la prohibición del artículo 108.3 TFUE, el órgano jurisdiccional nacional tendrá que interpretar y aplicar el concepto comunitario de ayuda, y ello porque si la medida no fuese tal no estaría sujeta a la prohibición de ejecución por falta de comunicación previa. Puede suceder, no obstante, que cuando se requiera la intervención del juez nacional, la Comisión haya iniciado el procedimiento de investigación de la ayuda considerada como existente (aunque otorgada sin autorización), en cuyo caso el juez quedará desapoderado para intervenir. Y puede suceder, asimismo, que, incluso tras apreciar la ilegalidad de la ayuda, la Comisión llegue a declararla compatible con el mercado común, aunque obsérvese que no por ello quedará subsanada la ilegalidad formal, con lo que se plantea el problema de su devolución. Un problema que, también con gran pragmatismo, se ha resuelto no exigiendo sino la devolución de los intereses desde la fecha del otorgamiento de la ayuda hasta la decisión de compatibilidad que haya adoptado la Comisión, pues, en otro caso, formalmente habría que reembolsarla y reiniciar el procedimiento a fin de notificarla y seguidamente, una vez autorizada, proceder a un nuevo otorgamiento ${ }^{25}$.

24 He analizado las funciones de la Comisión Nacional de los Mercados y la Competencia respecto del control de los efectos de las ayudas sobre el mantenimiento de la competencia efectiva en los mercados en J. Folguera Crespo et al. (dirs.), Comentario a la Ley de Defensa de

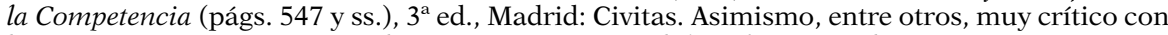
la carencia que en este particular extremo presenta el derecho español, J. E. Soriano García y M. M. SÁNCHEz GutiéRREz (2005), «El control de las ayudas públicas en España: un contexto a cambiar», en La modernización del Derecho de la competencia en España y en la Unión Europea (págs. 299 y ss.), Madrid: Marcial Pons.

${ }^{25}$ Los problemas a los que se enfrenta el juez en el control — limitado, pero efectivo- de las ayudas de Estado no se agotan con lo dicho. Ilustrativo puede ser este otro supuesto. La 
Resta añadir que el juez nacional también puede controlar la aplicación que el Estado hace de los Reglamentos comunitarios de exención, de manera que si, a instancia por ejemplo de una empresa competidora, verifica que la ayuda otorgada no cumple los requisitos del Reglamento, podrá declarar que la ayuda es ilegal por no haberse notificado a la Comisión. De este modo, aunque los particulares no pueden invocar aisladamente el artículo 107.1 TFUE para pretender la declaración de incompatibilidad por el juez nacional, lo que sí pueden es invocar el incumplimiento de los requisitos y condiciones del Reglamento que, de manera clara e incondicional, ha establecido que determinadas ayudas no lo son a los efectos del referido artículo. En definitiva, si la medida adoptada por el Estado cumple los requisitos del Reglamento de exención, el juez rechazará el recurso y declarará legal la ayuda. Pero en caso contrario, no podrá declarar su incompatibilidad por razones de fondo, aunque sí constatará la ilegalidad y anulará el acto, adoptando las medidas que procedan (recuperación, en su caso, de la ayuda).

Por lo demás, también las decisiones de la Comisión sobre ayudas producen efecto directo y el juez nacional es competente en eventuales litigios sobre el cumplimiento de decisiones negativas o en el control de decisiones positivas de la Comisión.

\section{Apostilla final}

Como es natural, la exposición que antecede no pasa de ser una aproximación de trazo grueso a los problemas y dificultades que encierra la aplicación del régimen de las ayudas de Estado, tanto por las autoridades comunitarias como, de manera más limitada, por las nacionales. Pero con lo dicho puede bastar para apreciar que la integración comunitaria - y con ella, la sujeción al derecho de la Unión Europeaha estimulado de manera importante la modernización de una trascendental parcela de la acción administrativa que, sin embargo, por razones fácilmente discernibles, se mantenía de espaldas al derecho. La sujeción al control comunitario de las ayudas económicas públicas, tradicional-

declaración de ilegalidad del juez nacional presupone que la medida es una ayuda, pero, como ya se ha apuntado, dilucidar si una medida es ayuda o no, a los efectos de la obligación o no de notificar a la Comisión, dependiendo de ello la legalidad o ilegalidad de la medida, ¿puede hacerse sin más o se debe plantear cuestión prejudicial ante el Tribunal de Justicia? Posiblemente pueda defenderse que no tiene por qué plantearse la cuestión, pues ante la decisión del juez que considera que se trata de una ayuda de Estado, el asunto podría llevarse ante la Comisión, de manera que si esta estimara que no es ayuda (y, por tanto, no procedía notificación alguna) se impondría su decisión. Con todo, como se ve, la cuestión no deja de ser problemática. 
mente concebidas como fruto de la libérrima y graciable voluntad de la Administración, no ha dejado de influir en la rectificación que finalmente se ha impuesto. Quedan, desde luego, cuestiones por abordar y resolver desde el plano estrictamente técnico-jurídico y, sobre todo, de la gestión y el control, sin desconocer, por lo demás, que sobre este tipo de actividad, por su naturaleza misma, siempre planeará el debate y la polémica. Pero, en cualquier caso, es incuestionable que el establecimiento de un marco normativo completo regulador del uso de tan importantes instrumentos ha supuesto para el ordenamiento jurídico español un cambio de extraordinaria relevancia. Como también lo es que, en su consecución, al igual que en tantos otros sectores y materias, el influjo comunitario ha terminado siendo decisivo. 